\title{
La Sanidad en los presidios del Reino. Real Ordenanza General de presidios de 1834*
}

\author{
J Leiva-Tapia
}

Jurista del Cuerpo Superior de Técnicos de IIPP

\section{RESUMEN:}

En el S. XIX, aparece en España el concepto “Sanidad penitenciaria” en el ordenamiento legal como elemento propio de las prisiones. En este siglo, gracias a una serie de principios ideológicos de carácter humanitario y progresista, se regulan y decretan normas que organizan la necesidad de una adecuada atención médica en los presidios de África, en los peninsulares, insulares y de ultramar. La más importante de ellas en aquella época, la constituyó la Ordenanza General de los Presidios del Reino de 1834, y el posterior Reglamento de 1844.

Palabras clave: Prisiones; España; Salud; Legislación; Historia del Siglo XIX; Enfermería; Alimentación; Terapias Espirituales.

\section{HEALTH CARE IN THE PRISONS OF THE KINGDOM. GENERAL ROYAL ORDINANCE OF PRISONS OF 1834\%}

\section{ABSTRACT:}

In the 19th century, the concept of "prison health" began to make an appearance in Spanish legislation as an integral part of prison management. Thanks to a series of ideological and progressive principles in the same century, laws were decreed and regulated to address the need for adequate medical care for prisoners in Africa, Spain and the overseas territories. The most important of these was the Royal Ordinance of Prisoners of the Kingdom of 1834, and subsequent Regulation of 1844.

Keywords: Prisons; Spain; Health; Legislation; History, 19th Century; Nursing; Feeding; Spiritual Therapies.

Fecha de recepción: 10-12-2014

Fecha aceptación: 23-05-2015

\section{Ordenanza General de los presidios del Reino de 1834}

"Deseando el Rey mi augusto y difunto Esposo (Q. E. E. G.) poner término al estado de desorden en que por lo general se hallan los presidios del Reino, se dignó nombrar en 30 de Setiembre de 1831 una Comision compuesta de personas celosas y conocedoras de las necesidades de dichos establecimientos, para formar un reglamento general que conciliase la vindicta pública y la corrección de los penados con las atenciones de humanidad y de economía.

Oidos los dictámenes del Consejo de Gobierno y del de Ministros, be tenido á bien decretar en nombre de mi augusta Hija la Reina Doña Isabel II, la siguiente Real Ordenanza General de los Presidios del Reino.”

María Cristina de Borbón-Dos Sicilias

Regente y Gobernadora del Reino

Villa y Corte de Madrid, a 14 de Abril de 1834

\footnotetext{
* El Consejo Editorial, por su interés y relevancia, ha aceptado publicar con carácter excepcional este artículo.
} 


\section{CONTEXTUALIZACIÓN}

Para la realización de este trabajo se ha consultado Legislación Histórica de España del Fondo Contemporáneo del Archivo Histórico Nacional y la Colección Legislativa de Presidios y Casas de Corrección de Mujeres de la Biblioteca de Don Antonio Cánovas del Castillo. 1861.

Estamos en los inicios de la época reformista penitenciaria. De hecho esta Ordenanza se considera el punto de salida desde donde el Coronel Montesinos ideó y aplicó el "sistema progresivo renovador".

Fue dictada por Isabel II de Borbón. Bueno, a mejor entender, por su madre la Regente, porque Isabel tenía apenas tres años de edad cuando accedió al trono tras la muerte de su padre Fernando VII. Tras el exilio de su madre, María Cristina de Borbón-Dos Sicilias, y una segunda Regencia fallida del General Espartero, militar liberal progresista, y con el propósito de evitar una tercera regencia, quedó decidido adelantar la mayoría de edad a Isabel, siendo proclamada en 1843, con tan solo 13 años, Reina in pectore.

La Ordenanza General de Presidios del Reino se debe en gran parte a la autoría del General Abadía, olvidado y poco reconocido por la historia, aunque precursor penitenciario y casi coetáneo de Montesinos, quien presidió la Comisión de notables penitenciarios, más militar que civil, creada en virtud de Real Orden de 30 de septiembre de 1831 por Fernando VII. Comisión ésta que organizó la administración y gobierno de los presidios "bajo un plan mejor entendido que conciliase la vindicta pública y la corrección de los penados con las atenciones de humanidad y de economía” y que desembocó en la Ordenanza de 1834.

Si bien la Ordenanza no fue cumplida escrupulosamente por los Comandantes-Directores de los Presidios (a excepción de Montesinos en Valencia), y por ello, algunos autores como Rafael Salillas (Médico e Inspector de Servicios Sanitarios de Prisiones en 1880) hablaron de un "código penitenciario inmaculado y profanado a la par". En parecidos términos se expresaba su enemigo doctrinal Fernando Cadalso y también la penalista Concepción Arenal se mostró muy crítica con la infausta vida de los encarcelados en los presidios de aquella época.

No obstante, esta cuestión no iba a ser ajena a los propios autores de la Ordenanza, por lo que en su articulado ya preveían eventuales incumplimientos, y así se establecía que:

"Como la experiencia tiene acreditado que los reglamentos mejor meditados son de poco utilidad cuando no concurren á mantenerlos la eficaz accion de los Jefes y la decidida voluntad de los empleados, procurará el Director general formar é introducir en los establecimientos de su dependencia un espiritu de cuerpo tal, que se obtenga por su medio lo que jamás se podría lograr con simples prevenciones. El Director Me propondrá las medidas que estime conducentes para la consecución de este importante objeto, y Me dará noticia de los empleados que mas se distingan por su celo y exactitud en el cumplimiento de sus deberes para la oportuna remuneracion de sus servicios."

"Al Director general corresponde: Proponerme personas idóneas para los destinos [...]. Por último, nombrar por sí á los que considere á propósito para desempeñar los demas encargos ó comisiones de presidios, y exonerar de ellos á los que no merezcan su confianza, formando antes un expediente reservado é instructivo de los motivos que aconsejen esta medida."

Constituyó un "Código Penitenciario fundamental" y, en palabras de García Valdés, "el primer Reglamento Penitenciario de España". Por otra parte, la primera Ley penitenciaria con ese rango legal, la Ley de prisiones de 1849 , vendría a ser "más administrativa” y con escasez de contenido penitenciario.

La Ordenanza Real de Presidios está escrita en primera persona (la Regente, en nombre de su hija la Reina), usando un lenguaje textual de ritual regio, muy directo y poco ceremonioso, si lo comparamos con las Reales Pragmáticas de monarcas anteriores. Es exhaustiva en su normativa y pormenoriza al detalle la vida presidial de la época, llena de curiosidades que hoy, transcurridos 180 años, nos parecen lejanas y casi anecdotario.

\section{CLASES DE PRESIDIOS Y DESTINO DE LOS PRESIDIARIOS}

\section{Ordenanza General de los presidios del Reino de 1834 y otras Ordenes Reales posteriores}

Con la Ordenanza Real había tres tipos o clases de presidios:

- Depósitos correccionales: hasta 2 años de condena, $1^{a}$ clase.

- Presidios Peninsulares: de 2 a 8 años, $2^{a}$ clase.

- Presidios de África: más de 8 años, con o sin retención posterior, $3^{a}$ clase.

Se establecieron los "puntos en que deben establecerse los presidios” y, así, se fijaron depósitos correccionales en las capitales de provincia donde ya existían, se ampliaron a alguna más y se dejó abierta la posibilidad de establecerlos en las demás capita- 
les donde se creyera conveniente. Se establecieron 7 presidios peninsulares (Barcelona, Valencia, Granada, Sevilla, Valladolid, Coruña y Zaragoza) y 4 en África (Ceuta, Melilla, Alhucemas y Peñón de Vélez de la Gomera). También había destacamentos insulares en Baleares y Canarias, y se mantenía el cumplimiento de pena con destino a las milicias en los Dominios de Ultramar al servicio de las armas en las guarniciones de Cuba, Puerto Rico y Filipinas.

Los depósitos correccionales de rematados (condenados) y presidios, servían también como lugares de concentración para destino a obras públicas y formación de brigadas para nutrir los destacamentos penales de Pajares, Cabrillas, Canal de Isabel II, Canal de Urgel, Canal de Castilla, carreteras, tendidos de ferrocarril y obras de fortificación civil en Jaca, Santoña, Cádiz, etc, o militares en las plazas de África.

En esta época, los presidios pasaron a ser competencia del Ministerio del Fomento General del Reino $y$, aunque la disciplina en su régimen interior seguía siendo militar, comenzaban a "descargarse" de la dependencia jerárquica directa del Ministerio de la Guerra, reconociéndose su condición civil y dependencia de la "Dirección General de Presidios", no obstante ser los encargados de su gobierno interno miembros en comisión procedentes de los Ejércitos o la Armada.

Resalta la importancia de la Ley de Prisiones de 1849, de "Régimen General de Prisiones, Cárceles y Casas de Corrección", que marcó un punto de inflexión al separar los establecimientos penitenciarios en dos áreas: la de prisiones civiles (dependientes ahora del Ministerio de Gobernación en cuanto a su régimen interior y administración económica), y las militares (dependientes del Ministerio de la Guerra), mientras que Marina siguió al mando de los Presidios Navales o de Arsenales (pena sustitutiva de la del remo en galeras), en Cádiz, Cartagena y Ferrol. Esta ley resolvió el problema de competencias al redistribuir las prisiones y ajustarlas al mandato legal, reglamentando su mando civil o castrense.

La ley dividió los establecimientos penitenciarios civiles en: Depósitos municipales, Cárceles de partido, Cárceles de capitales de audiencias y Establecimientos penales.

\section{LA SANIDAD PENITENCIARIA EN EL SIGLO XIX}

\section{Ordenanza General de los Presidios del Peino de 1834 y otras Ordenes Reales posteriores}

En el S. XIX, aparece en España el concepto "Sanidad penitenciaria" en el ordenamiento legal como elemento propio de las prisiones. En este siglo, gracias a una serie de principios ideológicos de carácter humanitario y progresista, se regulan y decretan normas que organizan la necesidad de una adecuada atención médica en los presidios de África, en los peninsulares, insulares y de ultramar.

La más importante de ellas en aquella época, la constituyó la Ordenanza General de los Presidios del Reino de 1834, y el posterior Reglamento de 1844 (atribuido a Montesinos) del Ministerio de la Gobernación, y que se dicta por Real Orden, aprobando los "reglamentos y formularios relativos al órden y mecanismo interior de los presidios del Reino, al suministro de rancho y utensilios, al régimen de escuelas y enfermerías, al abono de pluses de confinados y al sistema de contabilidad".

De este modo, se destaca entre las obligaciones de los Comandantes de presidios, establecer una enfermería en algún departamento del presidio para alojar y asistir á los enfermos de poca consideración y á los convalecientes, y evitar en cuanto sea posible la traslación de ellos al hospital, con cuyo objeto cuidará de que haya en el establecimiento un botiquín provisto de lo más esencial, que estará á cargo del Médico-cirujano del presidio.

También en el Reglamento de 1844 se añade que los Comandantes de los presidios visitarán la enfermería, se enterarán de su asistencia, alimentos, limpieza y salud de los enfermos, procurando que este local se sitúe en aposentos altos, claros y bien ventilados; probarán los caldos y darán cuantas disposiciones crean conducentes al alivio y consuelo del desgraciado paciente, haciendo que el Facultativo llene sus deberes, y que después de sus visitas pase a enterarle individualmente del estado de salud de los enfermos de más gravedad y de sus disposiciones.

Por Real Decreto también de 1844, se reduce el número de presidios, modificando la plana mayor de los que han de subsistir, quedando el organigrama de cada presidio como sigue. Cada presidio tendrá una plana mayor compuesta por:

$1^{\circ}$. Un Comandante (sueldo de diez y seis mil reales al año)

$2^{\circ}$. Un Mayor (diez mil reales)

$3^{\circ}$. Uno o dos Ayudantes (seis mil reales)

$4^{\circ}$. Un Furriel (cuatro mil reales)

$5^{\circ}$. Un Capellán (tres mil trescientos reales)

$6^{\circ}$. Un Médico-Cirujano (cuatro mil cuatrocientos reales)

$7^{\circ}$. Un Capataz por cada cien confinados (tres mil reales) 
Finalmente, los Cabos de varas, presidiarios sin grilletes, con gratificación de 180 reales. Eran los cabos presos de confianza nombrados por el Comandante encargados de la vigilancia del resto de reclusos y de impartir "a golpe de vara" gran parte de la disciplina en los penales.

En cuanto a las Enfermerías, la Ordenanza General de Presidios establece que en todos los depósitos y presidios habrá un departamento destinado á enfermería, que se establecerá en habitación alta de techo, ventilada, y siendo posible, elevada de la superficie de la tierra dos varas á lo menos para evitar toda humedad.

Cuando el local de algún establecimiento penal no permita colocar la enfermería dentro del mismo recinto, pedirá el Comandante la guardia militar que estime conveniente para la debida custodia de los penados en el hospital.

La Real Orden de 14 de septiembre de 1838, manda que se admita á los presidiarios enfermos en los hospitales civiles y eclesiásticos, y sólo en los militares en el caso en que por las circunstancias de un momento así lo dicte la humanidad y aconseje una justificada necesidad, entendiéndose entonces que por el presupuesto del Ministerio de la Gobernación se abonará al de Guerra, no solo los cuatro y medio reales asignados por cada estancia de hospitalidad en la Ordenanza de presidios, sino también el exceso hasta cubrir el precio á que resulte la estancia. Esta Real Orden fue consecuencia de expediente instruido á consecuencia de haberse reclamado contra la resistencia opuesta por el Intendente militar del distrito de Galicia á la admisión y asistencia en el hospital militar de la plaza de la Coruña de los presidiarios enfermos del correccional de la misma.

Continúa la Ordenanza de Presidios describiendo el local de la enfermería: será una sala proporcionada al número de camas que se calcule puedan necesitarse, y en cuya puerta habrá un centinela dependiente de la guardia. En la sala habrá una división ó separación, donde serán observados los que aparezcan con síntomas de enfermedades cutáneas ó contagiosas, hasta que declaradas tales se trasladen al hospital los que las padezcan. Lo mismo se hará con todos aquellos cuyas dolencias se hagan graves, pues la enfermería interior no es sino para las leves, ó para la convalecencia de las que se han curado en el hospital.

A la inmediación de la enfermería habrá cocina y aposento, si es posible, con azotea inmediata y agua dulce á mano para preparar los alimentos y las medicinas. En la misma habitación tendrá su habitación el Furriel, y si es posible el Médico del establecimiento.

Habrá en la enfermería una camilla cubierta y decente para conducir los enfermos al hospital, y con- forme la necesidad lo vaya exigiendo, el Ayudante, de acuerdo con el Facultativo y el Furriel, propondrá la compra ó adquisición de los efectos ó utensilios que se necesiten por medio de una nota que se presentará al Mayor, y con su orden se comprarán los artículos propuestos, sirviendo la misma nota de comprobante en la cuenta.

Si para asistencia de los enfermos se necesitasen algunos sirvientes, los pedirá el facultativo al Comandante, quien mandará al Ayudante que elija de entre los penados los que merezcan su confianza y sean á propósito para el servicio á que se les destina. Estos presidiarios disfrutarán en los días en que estén ocupados en la asistencia de los enfermos de un real de vellón diario.

Cuando haya enfermos, heridos o convalecientes en la enfermería, se nombrará todos los días un cabo de enfermería, alternando en este servicio los cabos de vara, propietarios é interinos, por pie de lista.

El cabo de enfermería permanecerá en ella sin separarse las veinticuatro horas de su guardia, cuidará de la vigilancia de los penados enfermos y de los asistentes, y será relevado todas las mañanas á la hora fija de la visita del Facultativo, á que deberá asistir con el cabo entrante por si ocurriese algo que mandarles.

Una Real Orden de Diciembre de 1885, se planteaba ya la desaparición de los cabos de vara, aunque finalmente los mantuvo por economía, cambiándoles la denominación por la de celadores. Así se disponía que "la actual organización de los establecimientos penitenciarios está llamada a sufrir radicales y profundas modificaciones a medida que los desahogos del Tesoro Público permitan llevar a la práctica los adelantos ya ensayados con éxito en las naciones más cultas. Pero mientras ese momento no llegue, se hace forzoso utilizar la reforma sin gravar el presupuesto ni ocasionar perturbación en los servicios. Entre los funcionarios que deben desaparecer, al menos con el carácter que hoy tienen, hállanse, en primer término, los llamados cabos de vara de los Presidios, pues repugna considerar como agente de la autoridad un individuo que por pertenecer a la clase de presidiarios, carece del prestigio indispensable para merecer el respeto y la obediencia de los penados. No es, sin embargo, hora todavía de sustituir o reemplazar a esos empleados, que en lo sucesivo se denominarán celadores, en la forma en que han de proveerse los demás cargos de los establecimientos de corrección como quiera que las circunstancias aconsejan atenerse a un plan de severas economías.”

El Furriel, bajo la dirección del Ayudante, llevará el cuaderno de alta y baja de la enfermería; correrá con los gastos, y presentará mensualmente las cuen- 
tas acompañadas de los documentos necesarios á la Mayoría con el cónstame del Facultativo y $V^{\circ} \mathrm{B}^{\circ}$ del Ayudante, con arreglo al formulario que en la misma Mayoría se le dará.

En el Reglamento sobre enfermerías de 1844 se establecía además que:

$1^{\circ}$. Se procederá á establecer en todos los presidios del Reino la correspondiente enfermería en la forma siguiente.

$2^{\circ}$. El local en que ésta se sitúe será elegido por el Facultativo del establecimiento, para que reúna todas las circunstancias de salubridad y anchura que ha de menester.

$3^{\circ}$. Este local se dividirá en dos secciones para que puedan estar con entera separación los de enfermedades contagiosas de aquellos que padezcan afecciones ordinarias.

$4^{\circ}$. Las enfermerías se dotarán con un número de camas igual al que resulte de un 7 por 100 de la fuerza que tenga cada presidio.

$5^{\circ}$. Las camas se compondrán de dos banquillos de media vara de alto ( $84 \mathrm{~cm}$ por vara); de tres ó cuatro tablas que describan vara y cuarta de ancho y dos y media de largo; de un jergón con cuarenta libras de paja preparada al efecto; de un colchón con una arroba de lana; de un cabezal con cuatro libras de ídem; de dos sábanas de tres varas menos cuarta de largo, una y media de ancho, y una manta de lana de iguales dimensiones.

$6^{\circ}$. Las camas del departamento de enfermedades contagiosas no tendrán colchón.

$7^{\circ}$. Habrá por cada cama una camisa de lienzo de cinco cuartas de largo y tres y media de ancho; un gorro de la misma tela de una tercia de largo; una mesa de pino blanca, de la altura de la cama y de media vara en cuadro, con su cajón; una servilleta cuadrada de tres cuartas; un tazón; una cuchara; un número de capotes para abrigo de los convalecientes, y un féretro para conducir los cadáveres al cementerio.

$8^{\circ}$. La ropa blanca de las camas ha de mudarse cada quince días con otra igual colada y lava$\mathrm{da}$; las camisas y gorros cada ocho; las servilletas cada cuatro; y los colchones, lana, jergones, mantas y tela de los cabezales cada seis meses.

$9^{\circ}$. La ropa, así como los demás utensilios y efectos que sirvan á los sarnosos, tiñosos, etc., se conservará y lavará con separación, sin mezclarla por ningún concepto con la destinada á los demás enfermos. $10^{\circ}$. Queda á juicio de las respectivas Juntas Económicas los demás útiles necesarios para el servicio.

La Ordenanza Real de Presidios regulaba bajo el mismo Título V la "asistencia espiritual y sanitaria", y establecía que habrá en cada establecimiento presidial un Facultativo Médico-cirujano, que nombrará el Director General donde no lo hubiere, de la clase de retirados del Ejército ó Armada, el cual, además del retiro, gozará la gratificación señalada á su destino.

El Médico-cirujano disfrutará, si fuere posible, pabellón en el departamento de la enfermería, y tendrá á su cargo el botiquín provisto de los medicamentos más indispensables.

Las obligaciones del facultativo eran:

$1^{\circ}$. Reconocer el estado de salud de todos los presidiarios de nueva entrada, tomando las disposiciones convenientes respecto de los enfermos.

$2^{\circ}$. Visitar todas las mañanas los depósitos del establecimiento para enterarse del estado de salud de los confinados, y disponer el pase de los enfermos á la enfermería ó al hospital, según fuere ó no de consideración la dolencia.

$3^{\circ}$. Reconocer diariamente las cuadras (dormitorios), cocinas y demás locales del presidio para que se conserven en el estado de aseo y limpieza correspondiente, así como las vasijas en que coman y beban los presidiarios, con especialidad las de cobre.

$4^{\circ}$. Concurrir sin demora a cualquier caso imprevisto de desgracia ó dolencia particular de los individuos del establecimiento y visitar dos veces al día a los enfermos y convalecientes que haya en la enfermería.

$5^{\circ}$. Entregar al Furriel papeletas firmadas de las medicinas y utensilios que se necesiten para la enfermería, a fin de que le sirvan de comprobante en su cuenta mensual, que revisará el Facultativo y a la cual pondrá su conforme.

$6^{\circ}$. En fin, proponer al Comandante, y establecer con su aprobación las medidas de higiene pública que considere convenientes para conservar la salubridad del establecimiento.

El Reglamento de 1844 regula también los alimentos que debían tomar los enfermos convalecientes, estableciendo que á todo confinado que sea alta en la enfermería se le suministrará los alimentos que prescriba el Facultativo en la forma siguiente: 
- Ración, ración y media ó tres cuartos de ración.

- Media ración: media y sopa.

- Sopa para la cena: hecha con dos onzas de pan hervidas en un tazón de caldo.

- Dieta animal y dieta vegetal.

La ración se compondrá de veinte onzas castellanas de pan y de doce de carne de carnero, ó en su lugar diez y seis de vaca; y si el Facultativo lo creyese necesario se le aumentará onza y media de garbanzos é igual cantidad de tocino; en cuyo caso se llamará ración completa; así como también las dos tazas de caldo, una por la mañana y otra por la noche, en caso de que el Facultativo no disponga otra cosa expresamente.

La dieta general se dividirá en animal y vegetal. Constará la primera de seis tazas de caldo repartidas al día, una cada cuatro horas, que se extraerán del todo de la carne señalada para ración, y además de dos onzas de jamón ó tocino para cada uno de los enfermos. El caldo que han de tomar los que estén á dieta animal debe hacerse poniendo por separado las doce onzas de carnero ó diez y seis de vaca, y las dos de jamón ó tocino correspondientes a cada uno de los enfermos. Extraída la sustancia de ambas materias se tendrá el mayor cuidado de que no se empleen otra vez en la enfermería, como tampoco los demás géneros que sobren.

La dieta vegetal será de sustancia de pan ó de arroz; consistirá en seis onzas de pan o cuatro de arroz cocidas en cinco libras de agua hervida hasta que quede reducida a la mitad; hecho el cocimiento, y antes de colado, se disolverán en él dos onzas de azúcar por cada enfermo.
Si el Facultativo prescribiese ración con vino se le dará un cuartillo, medida de Madrid, que se dividirá entre la comida y la cena. Si en algún caso dispusiese el Facultativo huevos ú otra cosa no señalada arriba, se suministrará rebajando su valor, cantidad ó sustancia de lo que le corresponda tomar a cada enfermo por su ración, en la inteligencia de que en la libreta ha de constar sólo la porción de alimentos prescrita generalmente en este reglamento.

Los Facultativos de las enfermerías usarán de las cifras siguientes para señalar en las libretas el alimento que crean deber prescribir á los enfermos, procurando siempre hacer las letras todas mayúsculas con bastante separación, y con tal claridad que no pueda haber equivocación:

- La ración con una $\mathrm{R}$.

- La ración y media ó tres cuartos con una $\mathrm{R}$ y una M.

- La media ración con una M y $\mathrm{R}$.

- La media y sopa con una M y una S.

- La dieta animal con una $\mathrm{D}$ y una $\mathrm{A}$.

- La dieta vegetal con una $\mathrm{D}$ y una $\mathrm{V}$

Otro apartado reglamentario viene referido a las medicinas. Los medicamentos ya simples ó ya compuestos, serán todos aquellos que están comprendidos en los formularios de medicina y cirugía hoy vigentes; pero de buena calidad, exactamente preparados y elaborados, y á cuyo fin estarán sujetos a la inspección del Facultativo y de un individuo de la Junta Económica.

\section{MODELO DEL RECETARIO.}

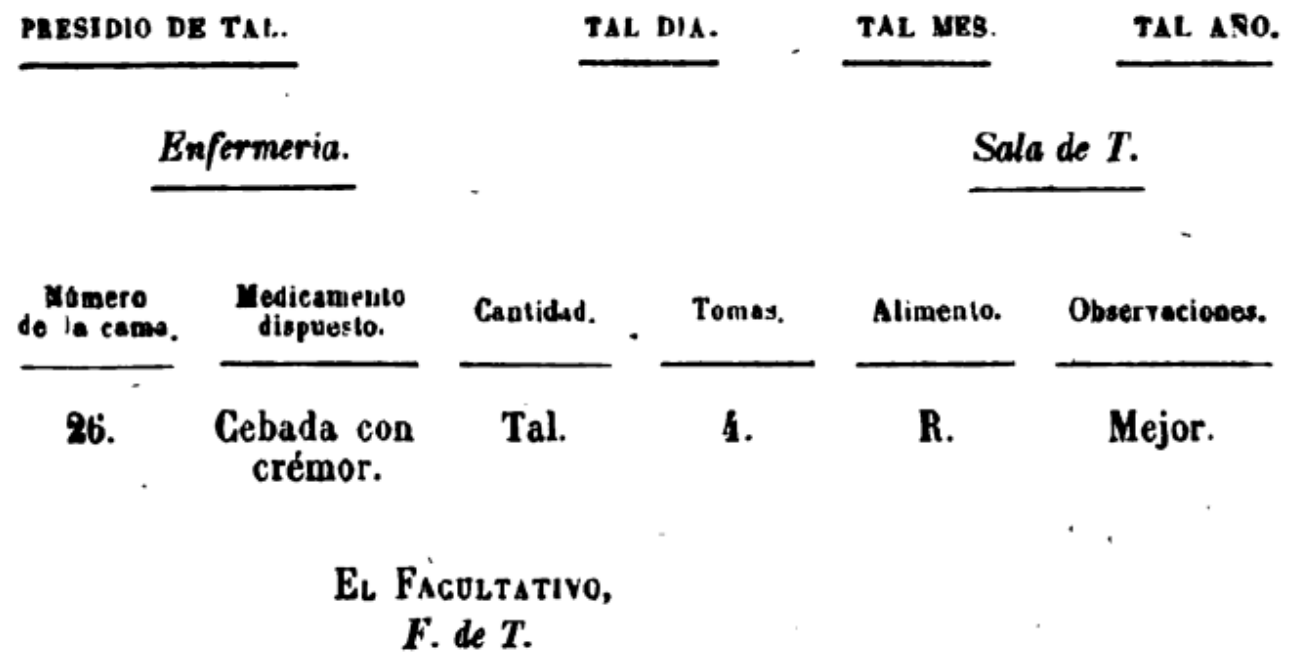


La clase de medicamento, su cantidad, modo y forma de administrarlo, lo señalará el Facultativo en el recetario que deberá abrirse en todas las enfermerías, según el modelo adjunto.

En un documento de la Cárcel de Ourense del año 1854, se trata del "Recetario de Medicina y Cirugía para los presos de la Cárcel Nacional", en donde aparecen algunos de los remedios prescritos a los presos: "Agua de Arroz, Agua de Cebada, Tisana de Grama, Tártaro emético, Sangrías ("de seis onzas", "de ocho onzas"), "una docena de sanguijuelas al epigastrio", Agua ardiente de Alcanfor..."

Finalmente, se establece que el Facultativo del presidio estará obligado a vivir en el establecimiento, y á visitar los enfermos tantas veces como la necesidad lo exija, á examinar los medicamentos y alimentos, y á dar parte al Comandante cuando los encuentre sin las circunstancias de perfección que reclama la humanidad doliente.

Ya se ha señalado con anterioridad, que la Ordenanza Real de Presidios regula bajo el mismo Título V la "asistencia sanitaria y la asistencia espiritual", por lo que no ha de extrañar la conclusión final, aún paradójica, de la normativa real de la época:

"Provistas ya las enfermerías de los establecimientos presidiales del Reino de todo lo indispensable para atender á la asistencia y curación material de los enfermos, solo resta procurar los medios para que se verifique á la vez la curación moral: á este fin, los Capellanes, como médicos de las almas, vivirán también dentro del establecimiento y asistirán constantemente a las enfermerias, para que con sus persuasiones y representación divina hagan llevar a los enfermos sus dolencias con resignación.

También será obligación de los Capellanes suministrar el Viático y la Extremaunción, ayudar á bien morir y acompañar al que cese de vivir al punto donde se le dé sepultura."

Jaime Leiva Tapia

\section{CORRESPONDENCIA}

Jaime Leiva Tapia

jaimeleiva62@gmail.com 